\title{
Assessment of Urban Growth Patterns using Spatio-temporal Data and Analysis
}

\author{
Said Masoud bakhit ${ }^{*}$, Sbai abdelkader ${ }^{2}$ \\ ${ }^{1}$ Statistical Centre for the Cooperation Council for the Arab Countries of the Gulf GCC Statistical Center \\ (Oman) \\ ${ }^{2} \mathrm{~S}$ Université Mohammed Premier, Oujda-Angad, Morocco \\ *Corresponding author's email: boras222 [AT] yahoo.com
}

\begin{abstract}
Modeling urban growth trends has become one of the critical issues in the last decades. This study aims to evaluate spatio-temporal urban growth trends using spatial modeling. For this purpose, four land-use maps were used to visualize historical urban growth trends in Seremban, Malaysia. Land Change Modeller (LCM) was used to evaluate the spatial trend of Land-use and land-cover (LULC) in Seremban. The results of the study confirm that urban areas in Seremban hugely increased from 1984 to 2010. The main reasons to increase urban areas are that economic and population growth in Malaysia in general and Seremban in particular. This study confirms that the LCM model is one of the effective spatial techniques that should be taken into account in urban planning studies.
\end{abstract}

Keywords - Urban growth, assessment, spatio-temporal, GIS, remote sensing

\section{INTRODUCTION}

According to [1], urban growth is a spatio-temporal and demographic operation that indicates the increased significance of metropolises, towns, and districts as a concentration of population in a particular economy and society. Therefore, the past and present status of urban growth patterns should be considered in the analysis process using Remote Sensing, GIS, and quantitative analysis.

Generally, rapid urban growth is a complex environmental issue because of the multiplicity of its patterns and its effects on the ecosystem [2]. Understanding the spatial patterns of urban growth is one of the most important challenges for researchers, planners, and decision makers in relation to achieving the principle of sustainable urban development (Fujita, 1976). In addition, comprehending the social, economic, and dynamic characteristics of urban growth will lead to the creation of effective policies that can address this phenomenon [3]. Generally, urban growth as a dynamic phenomenon is a result of several factors, such as population and economic growths. Conversely, it creates various effects, such as the reduction of agricultural and natural lands. Thus, further scientific studies are required to discover the best methods of evaluation and simulation that could assist in reducing its effects [4].

According to Bhatta [1], there are several potential causes and impacts of urban growth. The increase in the number of births compared to the number of deaths, and the consequences of rural-urban drift are the significant causes of the urban growth phenomenon. In addition, economic growth such as the increase in household income due to economic and commercial development also leads to an increase in the demand for lands of residence, living and property cost, credit and capital market, housing investment, and industrialisation. Moreover, physical geography is one of the important reasons of urban growth such as elevation from sea level, slope, and soil texture. The administrative aspect is also one of the major reasons of urban growth such as independence of decision of cities and urban areas, legal disputes, expectations of land appreciation, development and property tax, Public regulation, policies, Governmental development, lack of proper planning policies, and failure to enforce planning policies. Public services such as transportation, road networks, jobs, banking services, and communications and electronic services are considered the main factors that encourage people to move to urban areas, which in turn leads to a rise in demand for lands and houses, thus increasing the rate of urbanisation.

On the other hand, there are many negative impacts of urban growth that have been summarised by Bhatta (2010), and divided into different groups, namely: (a) Environmental impacts: there are many environmental impacts of urban growth e.g. the decrease in natural lands such as forest and grasslands as well as decreased agricultural areas. In turn, surface temperature, the impact on hydrological systems, air, soil, water, and noise pollution are increased; (b) Economic impacts, which include the increase in Public services and infrastructure costs as well as decreased productivity of agricultural areas; (c) Social impacts, which include poverty, health problems such as obesity, crime, the disintegration 
of families, etc.; (d) The lack of urban services such as running water, sewers, solid waste pickup, electricity service, and paved roads is one of the significant impacts of urban growth.

Shahraki, Sauri [5] suggest some guiding principles for urban and land-use planning such as acquiring and developing land utilisation, balancing regionally varied living conditions, and flexibility in selecting one's place of work and place of residence. Generally, urban land-use planning should include different principles, namely: (a) balanced sustainability, which meets social, economic, and environmental needs; (b) urban land-use planning must be legally binding; (c) urban land-use planning should be carried out through local, regional, and national institutions via effective partnership between these institutions; (d) social, academic, and student dialogue is an important part of urban land-use planning; (e) urban land-use planning should be a comprehensive process, which includes all stakeholder groups; (f) urban land-use planning should be realistic and be in the context of local conditions; (g) urban land-use planning should be in light of methodology that avoids unnecessary data and processes; (h) urban land-use planning should be related to spaces and places; and (i) urban land-use planning should be about mapping current land-use or land covers, as well as identifying how land will be used in the future [6].

Several indices have been used to measure urban growth patterns, such as mathematical and statistical indices [7]. These indices are integrated within a GIS environment and via RS data and techniques so that they can be used to measure land-use changes spatially and temporally [8]. Many traditional mathematical and statistical approaches are unsuitable for spatial studies such as urban studies for several reasons; for example, with the use of traditional mathematical and statistical approaches, summarising site information becomes difficult, and the effects of representation patterns in spatial data are different from those in statistical data [9]. Hence, mathematical and statistical methods have been integrated and developed with other modern techniques such as GIS and RS techniques to measure spatial dynamics and land-use changes [10]. These techniques can be used to better understand urban growth patterns in metropolitan areas provided that appropriate spatial data are made available [9].

Generally, various spatial statistical models have been employed for land-use analysis in urban regions [11]. Ren et al. (2013) applied Pearson's Chi-square statistics to analyse and evaluate the growth pattern and overall situation of urban sprawl. Punia and Singh [8] used Shannon's Entropy approach (Hn) to identify whether urban growth is compact or dispersed, as well as to determine whether or not urban sprawl exists. Aithal and Sanna [2] used alpha and beta population density metrics as indicators of urbanisation and urban growth. Ramachandra, Bharath [12] employed a landscape metrics to analyse, evaluate, measure, and compute urban growth patterns according to different matrices, such as the Landscape Shape Index (LSI) and Normalised Landscape Shape Index (NLSI). Suribabu, Bhaskar [13] used statistical change detection of land use to evaluate urban growth patterns.

Landscape metrics, Shannon's Entropy, Chi-square, UEI, and land-use change detection are significant techniques that have been used to measure and map urban growth patterns. Their significance is due to several reasons, such as their use of quantitative and optical measurements. Moreover, these techniques employ different methods for measuring urban growth patterns, such as measuring the changes of built-up areas to identify the type and degree of urban expansion [12] and mapping historical land use and land covers, to evaluate and monitor urban growth phenomenon over different time periods [13]. However, some measurement techniques such as Shannon's Entropy approach and density maps yield the same results and are similar in terms of measuring the compactness of built-up areas.

This study aims to use spatio-temporal data and analysis in the GIS environment to assess urban growth patterns in Seremban river basin, Malaysia. This study is the first of its kind in Seremban.

\section{METHODOLGY}

\subsection{Study Area}

Seremban River Basin is the largest district in the Negeri Sembilan State (Figure 1). Seremban is also the capital of Negeri Sembilan State. It occupies a total land area of approximately $441.98 \mathrm{sq} . \mathrm{km}$ and includes the districts of Seremban town, Setul, Labu, Rasah, Ampangan, Rantau, Pantai, and Lenggeng. Seremban is located approximately 20 $\mathrm{km}$ from Putrajaya, the national capital of Malaysia, and $67 \mathrm{~km}$ from Kuala Lumpur, the economic center of Malaysia. The population of Seremban is more than 500,000 and is expected to increase to 1,000,000 in 2020 [14]. 


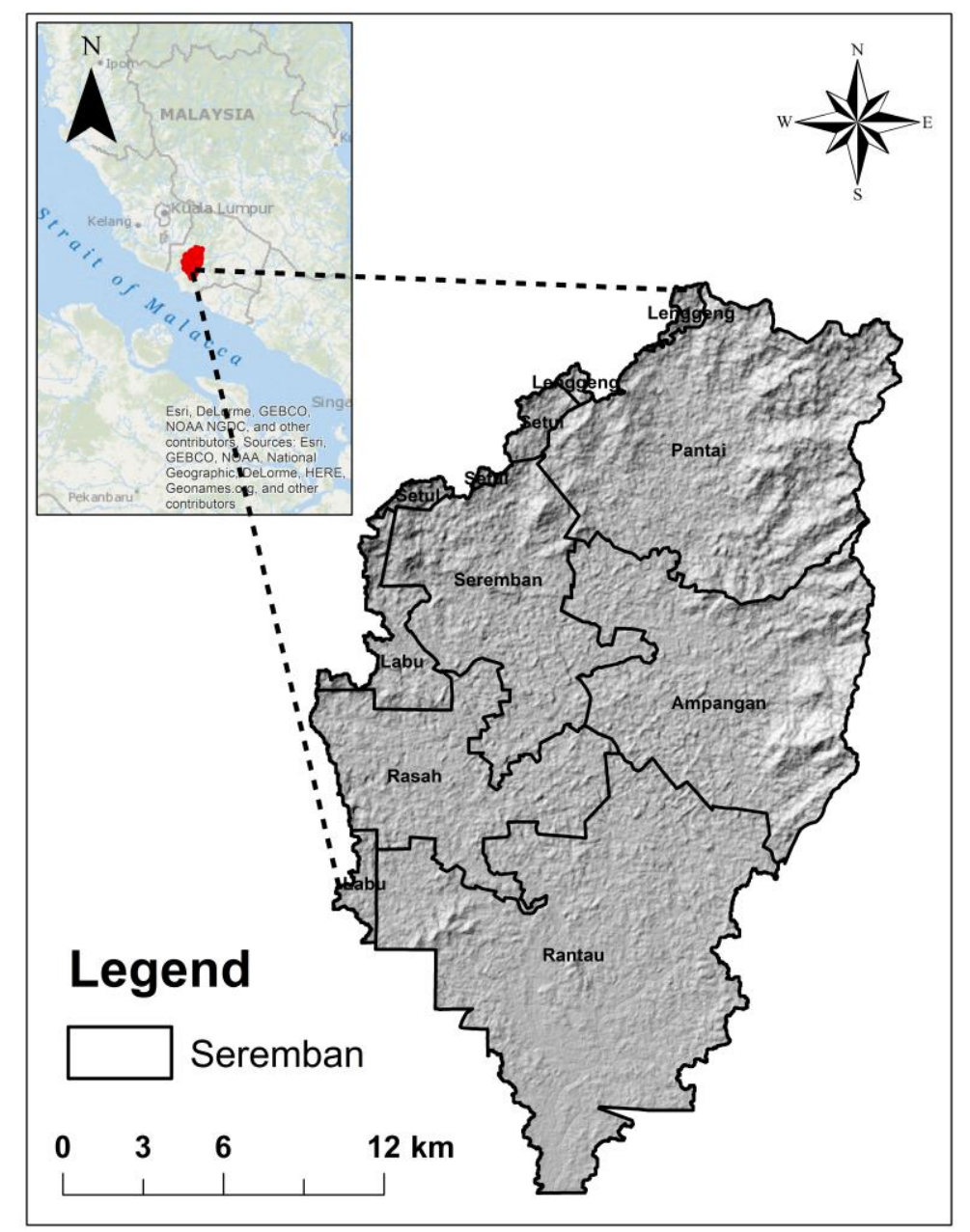

Figure 1: Study Area.

\subsection{Martials and Methods}

The main limitation in this study is the non-availability of new spatio-temporal data such as land-use maps that show land-use change in Seremban in 2019. However, the available land-use map data obtained from the Department of Agriculture Malaysia (DOA) were acceptable for achieving the main aim of this study, which is to assess urban growth trends in Seremban. Therefore, this study used land-use maps of 1984, 1990, 2000, and 2010 for the purpose of assessing and evaluating urban growth.

This study utilised land-use maps of 1984, 1990, 2000, and 2010 acquired from DOA (i.e. Department of Agriculture Malaysia). This study has used DOA maps because of that Land use map that created in DOA is one of the most accurate spatial data that is generated in Malaysia which employing Spot imagery for generating different types of land-use and GPS field data for validating the classification of land-use maps. Moreover, the classification of land-use maps is based on the urban planning process in different scales in Malaysia which make these maps more accurate and realistic. In addition, the classification of land-use maps of DOA is not only generated by the experts of Agricultural Department, but also by the experts of other Malaysian government institutions such as Department of Town and Country Planning. Furthermore, the spatial data from DOA can be collected as a shapefile format which can be easily used in GIS environment. Based on the interview with DOA technicians, the land-use maps were extracted from Spots 2, 4, and 5 images, with a $10 \mathrm{~m}$ and $2.5 \mathrm{~m}$ spatial resolution for Spots 2, 4, and 5, respectively. The pre-processing and processing stages of the satellite imageries were conducted in the Department of Agriculture Malaysia. The pre-processing and processing stages include spatial, radiometric, and spectral corrections. All satellite imageries were registered and corrected using ground control points from the field (i.e. a GPS)) and classified using image-enhancement techniques. DOA recommended that the supervised classification method be used to classify all images, so as to extract land-use categories. Additionally, ground control points were collected to evaluate the accuracy of the satellite image classification in this study. Based on the Department of Agriculture Malaysia, the values of classification accuracy were found acceptable. The acceptable values of classification accuracy should be more than 0.85 [15]. Generally, land-use 
maps generated by the DOA are considered accurate sources for any scientific research on Malaysia. They are also commonly used for Local, Federal, and National projects and for urban planning and environmental management purposes.

This study applied the accuracy assessment method for the 1984, 1990, 2000, and 2010 land-use maps. The main purpose of applying an accuracy assessment on the land-use maps is to ensure that the classification of land-use maps created by the Department of Agriculture Malaysia has acceptable values of accuracy. Based on an interview with DOA technicians, the land-use maps were extracted from SPOT 2, 4, and 5 images, with a $10 \mathrm{~m}$ and $2.5 \mathrm{~m}$ spatial resolution for SPOT 2, 4, and 5, respectively. The pre-processing and processing stages of the satellite imageries were conducted in the Department of Agriculture Malaysia, and include spatial, radiometric, and spectral corrections. All satellite imageries were registered and corrected using ground control points from the field (i.e. GPS) and were classified using imageenhancement techniques. DOA recommended that the supervised classification method be used to classify all images, so as to extract land-use categories. Additionally, ground control points were collected to evaluate the accuracy of the satellite image classification in this study.

The Kappa coefficient values were $0.83,0.85,0.90$ and 0.88 , respectively; while the overall accuracy values of the land-use maps were $86 \%, 88 \%, 92 \%$, and $91 \%$, respectively. This means that the accuracy of land-use classification meets the requirements of the study.

Land-use change-detection is one of the most widely used techniques for evaluating urban growth patterns. This study used the change-detection technique to evaluate urban development and its effect on land-use change in Seremban District. Four land-use maps from 1984, 1990, 2000, and 2010 were used to detect land-use change in Seremban. Landuse values were initially computed using a GIS environment. Then, mathematical methods were used to determine the amount of change in each category of land-use in Seremban from 1984 to 2010. The main reason for not using the landuse map of 2016 was because there was no available land-use map for that particular year at DOA. Additionally, Landsat images have low spatial resolution (i.e. $30 \mathrm{~m}$ ) compared with land-use maps generated using SPOT images that have high spatial resolution (i.e. 10 and $2.5 \mathrm{~m}$ ). This has led to the difficulty in establishing the 2016 land-use map that has the same categories of land-use with other land-use maps used in this study. Moreover, the concept of image classification at DOA relies on official land-use planning more than visualization, which means that the image classification for the 2016 Landsat image, which relies on visualization, will lead to different results for the area of land-use compared with the official land-use maps of DOA. In this study, the land-use-change-detection technique was used to determine urban growth patterns in Seremban in which visual and statistical methods were employed (Figure 2). The visual method was conducted by visualizing the land-use types into maps and allowing the readers to easily understand the issue of urban growth. Meanwhile, a Land Change Modeler (LCM) was used to generate the spatial dimensions of urban growth such as the land transition of urban area using IDRISI Selva 17.0.

LCM is widely used for ecological sustainability. This model was integrated with IDRISI Selva software. It is also available as an extension in the ArcGIS software. This extension is commonly used for addressing the pressing problem of accelerated land conversion [16]. Therefore, LCM was used in this study to measure the urban transformation in Seremban from 1984 to 2010 using land-use maps that were generated by DOA.

This extension includes several aspects such as land cover change analysis, land-use planning, land cover change prediction, and implications analysis that are used in different types of applications [16]. Since this part of the study focuses on land transformation, the land cover change analysis was used to identify the land-use change of urban areas. LCM was applied in three stages. First, the change map of each category from 1984 to 2010 was generated. Then, the table of land area of each category of land-use from 1984 to 2010 was created. Following that, spatial trends of change maps from 1984 to 2010 (the transition of all categories of land-use to built-up area) were applied. Finally, the transition maps from each category of land use to built-up area were generated. 


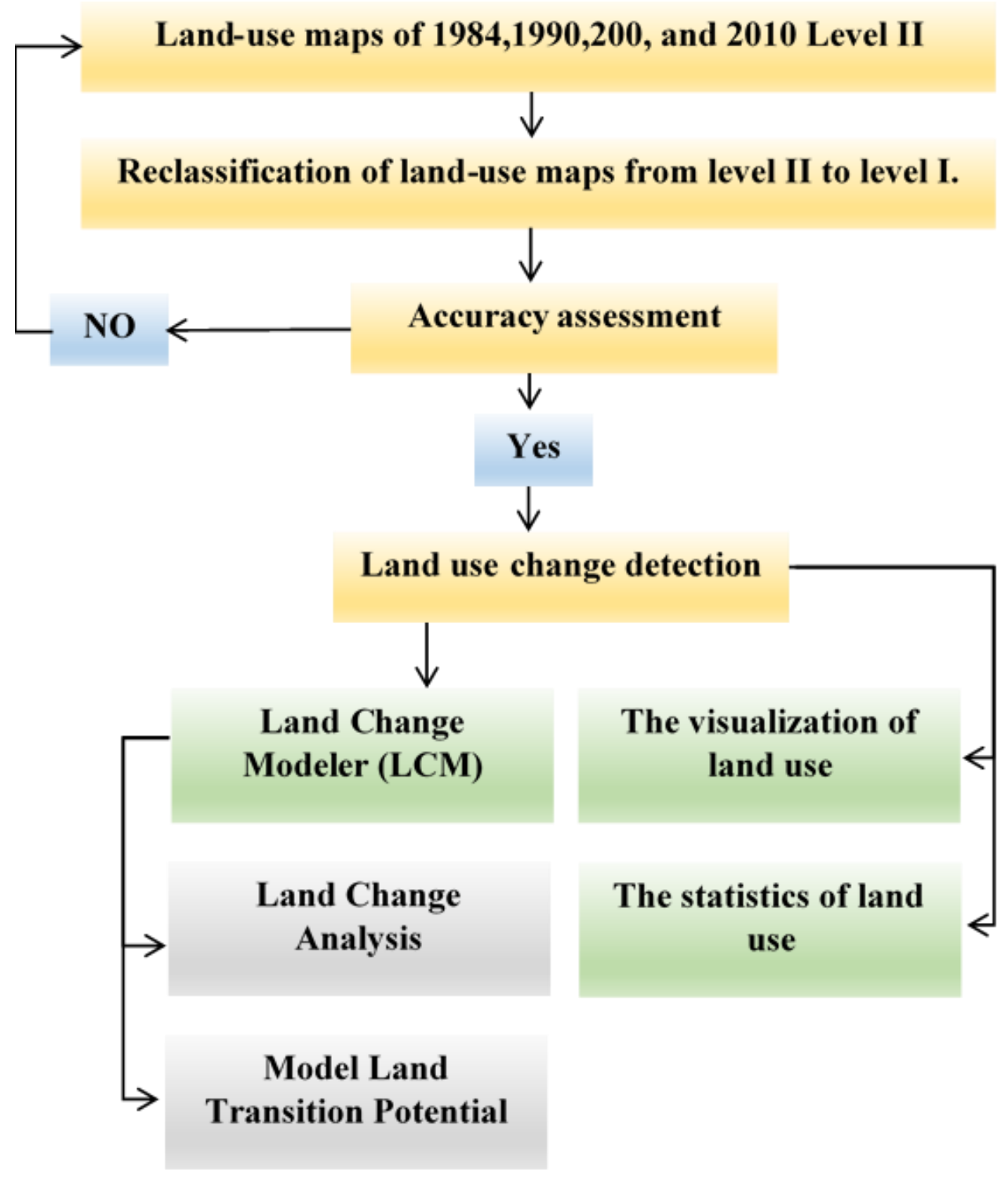

Figure 2: Operational Processes used to Conduct Land-use Change-detection.

\section{RESULTS AND DISCUSSION}

\subsection{Urban Growth Mapping}

Built-up maps provide a powerful visual explanation of urban growth in Seremban (Figure 3). The summary of visual presentation of built-up area in Seremban shows a rapid increase and dispersion of urban growth in 2000 and 2010 because of several factors, such as the population growth increase from 233086 persons in 1984 to 383530 persons in 2000 and to 627717.2 persons in 2010 [14, 17, 18]. The rising level of household income is a factor that significantly affects the rise of urban growth [4]. The rise in population growth and household income also increases the demand for houses and lands, which in turn leads to the issue of urban growth [19]. In this study, Pearson's correlation coefficient results confirmed a significant relationship among urban growth, population growth, and household income (Table 1). These results indicate that the effects of population and economic growth on urbanisation are extremely strong. Pearson's correlation coefficient values of urban growth with population growth and household income are 0.983 and 0.984 , respectively. 

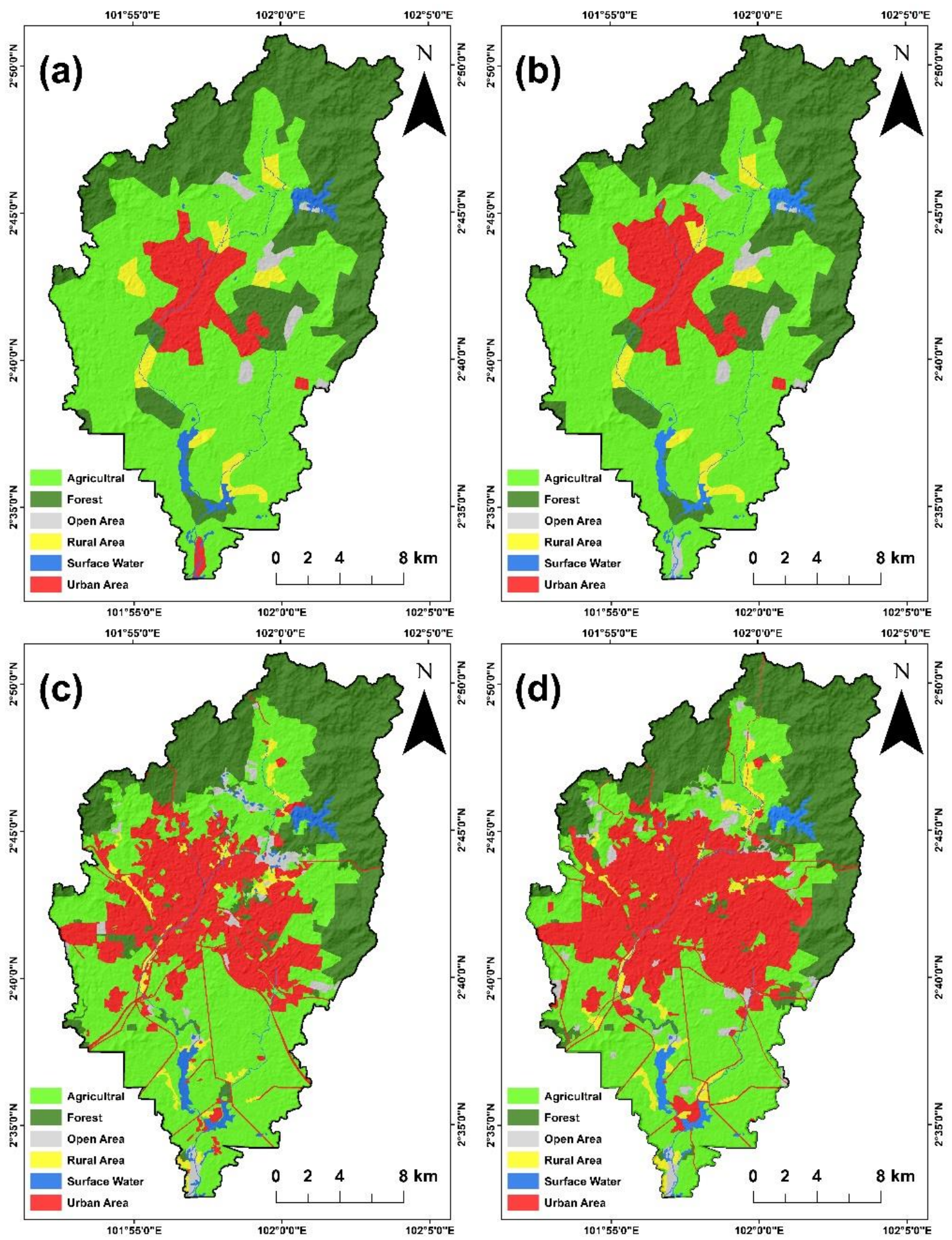

Figure 3: Land-use change and urban growth of Seremban River Basin: (a) 1984; (b) 1990; (c) 2000; and (d) 2010 .. 
Table 3: Relationship between Urban Growth, Population Growth, and Household Income in Seremban using Pearson's Correlation Coefficient..

\begin{tabular}{|c|c|c|c|}
\hline & $\begin{array}{c}\text { Urban } \\
\text { growth }\end{array}$ & $\begin{array}{c}\text { Population } \\
\text { growth }\end{array}$ & $\begin{array}{c}\text { Household } \\
\text { income }\end{array}$ \\
\hline $\begin{array}{c}\text { Urban growth } \\
\text { Pearson Correlation Sig (2- } \\
\text { tailed) N }\end{array}$ & 1 & 0.983 & 9.984 \\
\hline $\begin{array}{c}\text { Population growth } \\
\text { Pearson Correlation Sig (2- } \\
\text { tailed) N }\end{array}$ & 0.983 & 0.017 & 0.016 \\
\hline $\begin{array}{c}\text { Household income } \\
\text { Pearson Correlation Sig (2- } \\
\text { tailed) N }\end{array}$ & 0.017 & 1 & 0.998 \\
\hline
\end{tabular}

The significant changes in land use and land cover (LULC) in Seremban are shown in Table 2 and Figure 4. The calculation of land-use area confirms the increase in urban area from $34 \mathrm{~km}^{2}$ in 1984 to $126 \mathrm{~km}^{2}$ in 2010 in Seremban District. This increase in change rate can be due to the rapid development activities in the study area, namely higher population and increased household income. However, a significant decrease occurred in non-urban areas from 407.98 $\mathrm{km} 2$ in 1984 to $315.98 \mathrm{~km} 2$ in 2010 . Agricultural lands are highly suitable for new urban projects because they are located in low lands. In addition, the rural lands and forest also decreased, but at a lower rate compared to that of agricultural lands.

Table 2: Amount of urban growth changes observed in sq. km.

\begin{tabular}{|c|c|c|}
\hline & Urban & Non-Urban \\
& Areas & Areas \\
\hline 1984 & 34.00 & 407.98 \\
\hline 1990 & 39.00 & 402.98 \\
\hline 2000 & 97.00 & 344.98 \\
\hline 2010 & 126.00 & 315.98 \\
\hline $\begin{array}{c}\text { Annual growth rate } \\
(1984-1990)\end{array}$ & $2.3 \%$ & $-0.09 \%$ \\
\hline $\begin{array}{c}\text { Annual growth rate } \\
(1990-2000)\end{array}$ & $9.54 \%$ & $-0.65 \%$ \\
\hline $\begin{array}{c}\text { Annual growth rate } \\
(2000-2010)\end{array}$ & $2.65 \%$ & $-0.34 \%$ \\
\hline Total Change sq. km & +92 & -92 \\
\hline
\end{tabular}

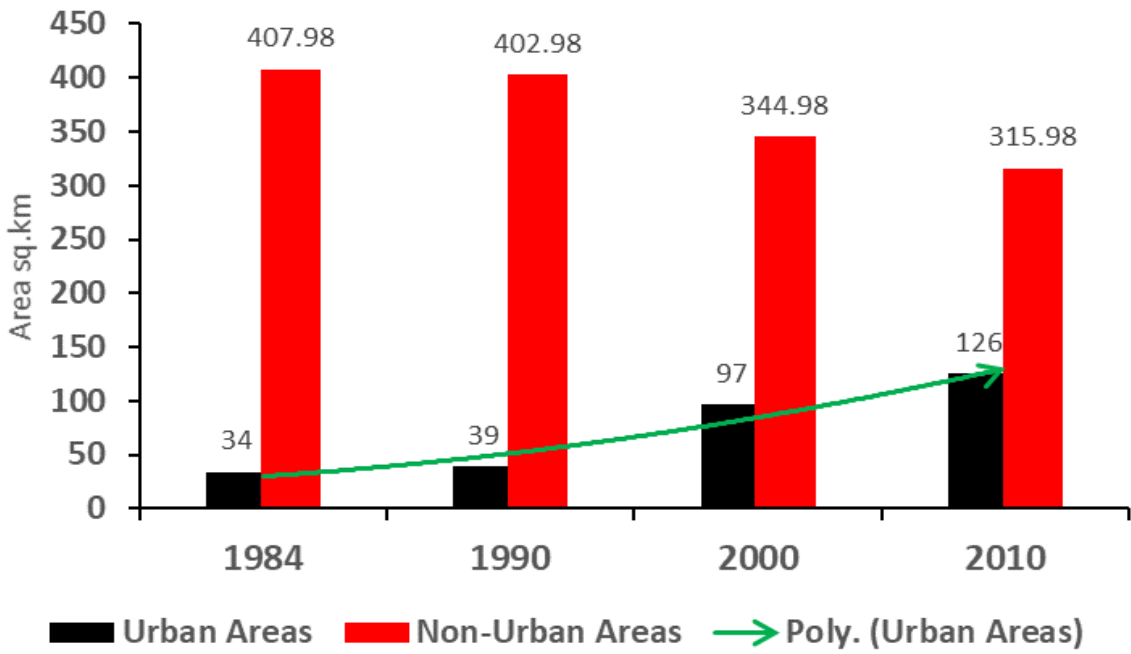

Figure 4: LULC Change in Seremban from 1984 to 2010 in km2. 


\subsection{Spatial Urban Growth Trends}

As shown in Table 3 and Figure 5, created using the Land Change Modeller (LCM), the built-up area (i.e. urban area), which denotes urban growth, has significantly affected agricultural land use in Seremban. The area of agricultural lands converted to built-up areas from 1984 to 2010 reached $68.3 \mathrm{~km}^{2}$. Such rapid conversion may affect the sustainability of agricultural lands in the long term. Meanwhile, $8.2 \mathrm{~km}^{2}$ of agricultural lands have been cleared (i.e. have become open areas) during this time. The agricultural lands in Seremban are ideal for new construction projects because their territory is low compared to forest lands that are located in high areas.

Table:3 Area Change for Each Category of Land-use using LCM $\left(\mathrm{Km}^{2}\right)$.

\begin{tabular}{|c|c|c|}
\hline No. of Class & Land use category & Area $\mathrm{Km}^{2}$ \\
\hline 1 & Forest to Agriculture & 19.3 \\
\hline 2 & Open Area to Agriculture & 2.6 \\
\hline 3 & Rural Land to Agriculture & 5.1 \\
\hline 4 & Urban Area to Agriculture & 2.3 \\
\hline 5 & Water to Agriculture & 0.0 \\
\hline 6 & Agriculture to Forest & 9.6 \\
\hline 7 & Open Area to Forest & 0.3 \\
\hline 8 & Rural Land to Forest & 0.0 \\
\hline 9 & Urban Area to Forest & 0.5 \\
\hline 10 & Water to Forest & 0.0 \\
\hline 11 & Agriculture to Open Area & 8.2 \\
\hline 12 & Forest to Open Area & 1.7 \\
\hline 13 & Rural Land to Open Area & 0.1 \\
\hline 14 & Urban Area to Open Area & 0.8 \\
\hline 15 & Agriculture to Rural Land & 6.4 \\
\hline 16 & Forest to Rural Land & 0.4 \\
\hline 17 & Open Area to Rural Land & 0.5 \\
\hline 18 & Urban Area to Rural Land & 0.5 \\
\hline 19 & Water to Rural Land & 0.0 \\
\hline 20 & Agriculture to Urban Area & \\
\hline 21 & Forest to Urban Area & 18.7 \\
\hline 22 & Open Area to Urban Area & 2.9 \\
\hline 23 & Rural Land to Urban Area & 6.7 \\
\hline 24 & Water to Urban Area & 0.0 \\
\hline 25 & Agriculture to Water & 0.0 \\
\hline 26 & Forest to Water & 0.0 \\
\hline 27 & Open Area to Water & 0.0 \\
\hline 28 & Rural Land to Water & 0.0 \\
\hline 29 & Urban Area to Water & 0.0 \\
\hline
\end{tabular}

Figure 6, created with the LCM, shows the spatial trend of change from each category of land use to urban area. The transition intensity from agricultural lands to urban areas is mostly occurring along the middle and northwest edges; this is because most of the agricultural lands and development projects in Seremban are located in these directions owing to the main highway that connects Seremban and KL. Meanwhile, the transition intensity from forestlands to urban areas is very low in the eastern, northern, and southern edges of Seremban because these edges are considered hilly areas that are not suitable for urban growth. It should be noted that water surface was not included because there is no transition from water to urban areas based on the LCM. The transition from categories of land use to built-up area is more intense along the west and northwest lines that run approximately across the middle of Seremban, with higher values at the middle and northwest edges of the image. The transition intensity is least along the eastern, northern, and southern edges of Seremban because these edges are made up of forest and hilly areas. 


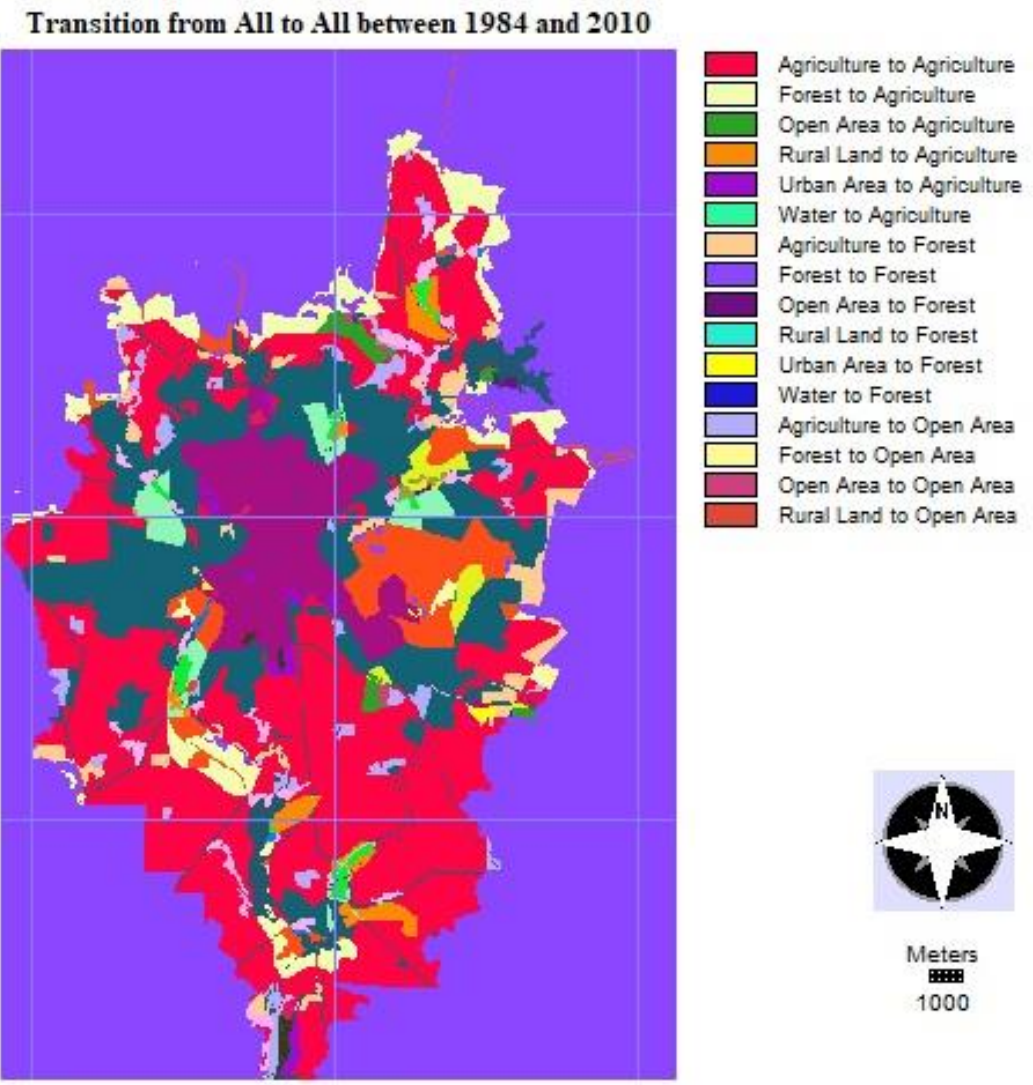

Figure 5: Transition from All LULC to All LULC between 1984 and 2010.

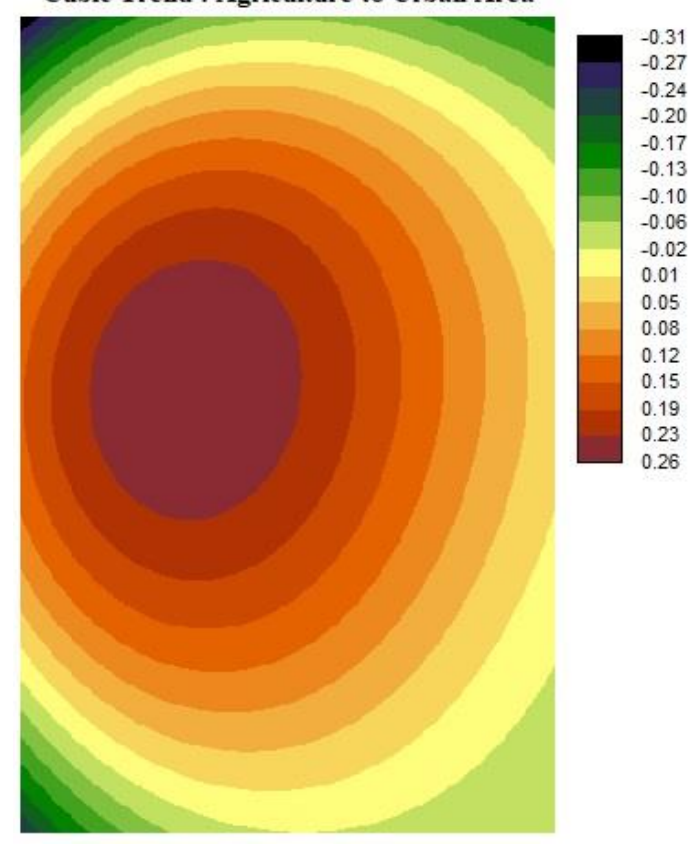

Cubic Trend : Forest to Urban Area

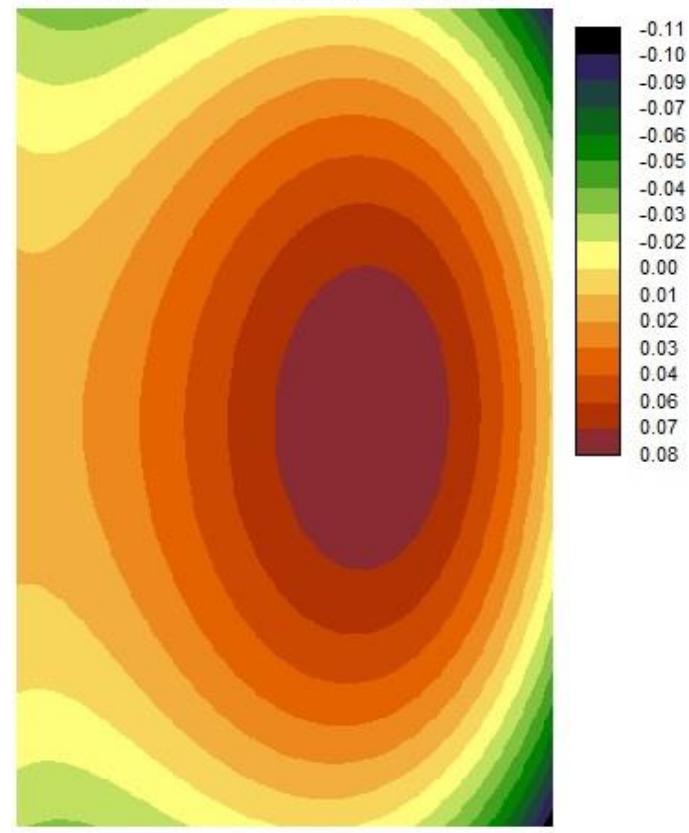



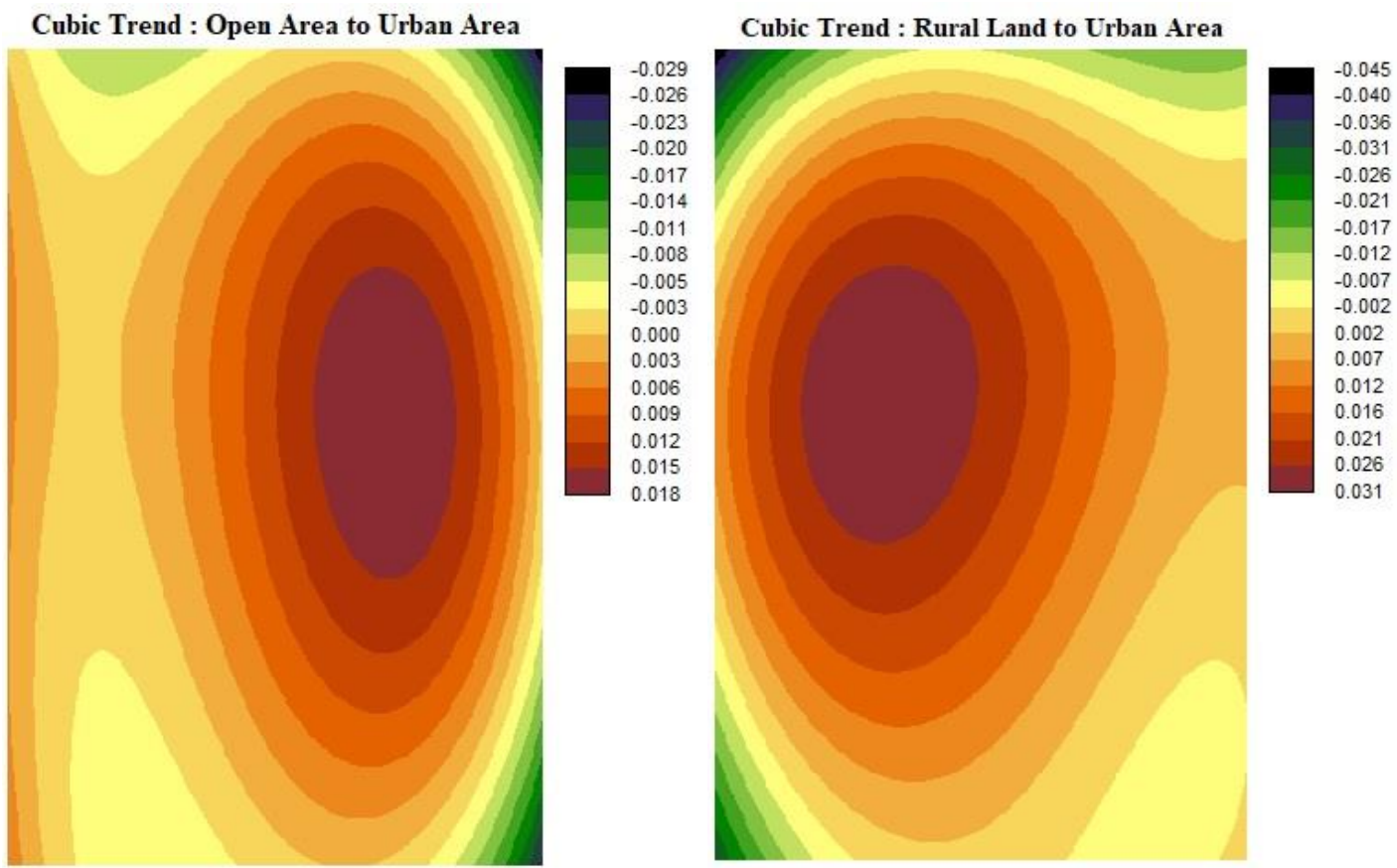

Figure 6: Spatial Trends of Change Map From 1984 to 2010 (The Transition of All Categories of Land-use to Builtup Area).

\section{CONCLUSIONS}

In this study, spatio-temporal data was used to evaluate urban growth trends in Seremban, Malaysia. The LCM model was used to calculate the spatial movement of urban development in Seremban. In addition, the LCM model was used to evaluate the change of land-use and land-cover in Seremban. Urban growth in Seremban rapidly increased between 1984 and 2010 due to population growth and economic development. This study concluded that spatial modeling should widely be used to improve the planning quality of urban planning. These types of spatial models should be involved in the urban planning process by decision makers and town planners. However, this study recommends that the efficiency of spatial models should be improved by integrating them with socio-economic models to obtain more realistic results of the urban growth issue.

\section{REFERENCES}

[1] Bhatta, Causes and Consequences of Urban Growth and Sprawl, in Analysis of Urban Growth and Sprawl from Remote Sensing Data. 2010, Springer. p. 17-36.

[2] Aithal, B.H. and D.D. Sanna, Insights to urban dynamics through landscape spatial pattern analysis. International Journal of Applied Earth Observation and Geoinformation, 2012. 18: p. 329-343.

[3] Habibi, S. and N. Asadi, Causes, results and methods of controlling urban sprawl. Procedia Engineering, 2011. 21: p. 133-141.

[4] Bhatta, S. Saraswati, and D. Bandyopadhyay, Quantifying the degree-of-freedom, degree-of-sprawl, and degreeof-goodness of urban growth from remote sensing data. Applied Geography, 2010. 30(1): p. 96-111.

[5] Shahraki, S.Z., et al., Urban sprawl pattern and land-use change detection in Yazd, Iran. Habitat International, 2011. 35(4): p. 521-528.

[6] Johnson, B.A. and K. Iizuka, Integrating OpenStreetMap crowdsourced data and Landsat time-series imagery for rapid land use/land cover (LULC) mapping: Case study of the Laguna de Bay area of the Philippines. Applied Geography, 2016. 67: p. 140-149.

[7] Jiang, F., et al., Measuring urban sprawl in Beijing with geo-spatial indices. Journal of Geographical Sciences, 2007. 17(4): p. 469-478.

[8] Punia, M. and L. Singh, Entropy approach for assessment of urban growth: a case study of Jaipur, India. Journal of the Indian Society of Remote Sensing, 2012. 40(2): p. 231-244.

[9] Ren, P., et al., Spatial Expansion and Sprawl Quantitative Analysis of Mountain City Built-Up Area, in GeoInformatics in Resource Management and Sustainable Ecosystem. 2013, Springer. p. 166-176.

[10] Aithal, B.H. and T. Ramachandra, Visualization of Urban Growth Pattern in Chennai Using Geoinformatics and Spatial Metrics. Journal of the Indian Society of Remote Sensing, 2016: p. 1-17. 
[11] Páez, A. and D.M. Scott, Spatial statistics for urban analysis: a review of techniques with examples. GeoJournal, 2005. 61(1): p. 53-67.

[12] Ramachandra, T., H. Bharath, and M. Sowmyashree, Analysis Of Spatial Patterns Of Urbanisation Using Geoinformatics And Spatial Metrics. Theoretical and Empirical Researches in Urban Management, 2013. 8(4): p. 5-24.

[13] Suribabu, C., J. Bhaskar, and T. Neelakantan, Land use/cover change detection of Tiruchirapalli City, India, using integrated remote sensing and GIS tools. Journal of the Indian Society of Remote Sensing, 2012. 40(4): p. 699-708.

[14] DOSM, Statistics Yearbook. Department of Statistics Malaysia, 2011: p. 367.

[15] Anderson, J.R., A land use and land cover classification system for use with remote sensor data. Vol. 964. 1976: US Government Printing Office.

[16] Labs, C., The Land Change Modeler for Ecological Sustainability. 2009: Clark University.

[17] DOSM, States/District Data Bank. Department of Statistics Malaysia, 1994: p. 249.

[18] DOSM, Preliminary Count Report. Department of Statistics Malaysia, 2000: p. 37.

[19] Doygun, H., Effects of urban sprawl on agricultural land: a case study of Kahramanmaraş, Turkey. Environmental monitoring and assessment, 2009. 158(1-4): p. 471-478. 